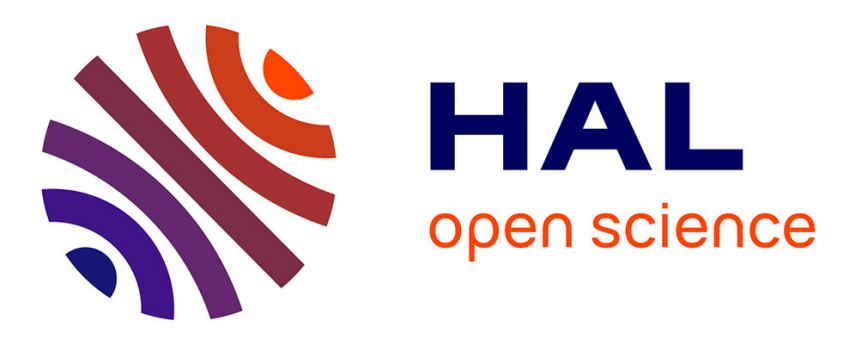

\title{
Thermal evolution of hydrated asteroids inferred from oxygen isotopes
}

\author{
Lionel Vacher, Maxime Piralla, Matthieu Gounelle, Martin Bizzarro, Yves
}

Marrocchi

\section{- To cite this version:}

Lionel Vacher, Maxime Piralla, Matthieu Gounelle, Martin Bizzarro, Yves Marrocchi. Thermal evolution of hydrated asteroids inferred from oxygen isotopes. The Astrophysical journal letters, 2019, 882, pp.L20. 10.3847/2041-8213/ab3bd0 . hal-02331795

\section{HAL Id: hal-02331795 \\ https://hal.univ-lorraine.fr/hal-02331795}

Submitted on 24 Oct 2019

HAL is a multi-disciplinary open access archive for the deposit and dissemination of scientific research documents, whether they are published or not. The documents may come from teaching and research institutions in France or abroad, or from public or private research centers.
L'archive ouverte pluridisciplinaire HAL, est destinée au dépôt et à la diffusion de documents scientifiques de niveau recherche, publiés ou non, émanant des établissements d'enseignement et de recherche français ou étrangers, des laboratoires publics ou privés.

\section{(ㄷ)(1)}

Distributed under a Creative Commons Attribution| 4.0 International License 


\title{
Thermal evolution of hydrated asteroids inferred from oxygen isotopes
}

\author{
Lionel G. Vacher ${ }^{1,2, *}$, Maxime Piralla ${ }^{1}$, Matthieu Gounelle ${ }^{3}$, Martin Bizzarro ${ }^{4} \&$ Yves
} Marrocchi $^{1}$

${ }^{1}$ CRPG, CNRS, Université de Lorraine, UMR 7358, Vandoeuvre les Nancy, F-54501, France ${ }^{2}$ Department of Physics, Washington University, St. Louis, MO, USA

${ }^{3}$ IMPMC, MNHN, UPMC, UMR CNRS 7590, 61 rue Buffon, 75005 Paris, France

${ }^{4}$ Centre for Star and Planet Formation and Natural History Museum of Denmark, University of Copenhagen, DK-1350 Copenhagen, Denmark

*corresponding author: 1.vacher@wustl.edu 
Chondrites are fragments of unmelted asteroids that formed due to gravitational instabilities in turbulent regions of the Solar protoplanetary disk. Hydrated chondrites are common among meteorites, indicating that a substantial fraction of the rocky bodies that formed early in the Solar System accreted water ice grains that subsequently melted due to heat released by the radioactive decay of ${ }^{26} \mathrm{Al}$. However, the thermal histories of asteroids are still largely unknown whereas it would bring fundamental information on their timing of accretion and their physical characteristics. Here we show that hydrated meteorites $(\mathrm{CM}$ chondrites) contain previously uncharacterized calcium carbonates with peculiar oxygen isotopic compositions $\left(\Delta^{17} \mathrm{O} \approx-2.5 \%\right.$ ), which artificially produce the mass-independent trend previously reported for carbonates. Based on these isotopic data, we propose a new model to quantitatively estimate the precipitation temperatures of secondary phases (carbonates and serpentine). It reveals that chondritic secondary phases recorded a gradual increase of the temperature during the extent of aqueous alteration, from $-10{ }^{\circ} \mathrm{C}$ to maximum $250{ }^{\circ} \mathrm{C}$. We also show that the thermal path of C-type asteroids is independent of the initial oxygen isotopic composition of the primordial water ice grains that they accreted. Our estimated temperatures for hydrated asteroids remain lower than those experienced by other 71 carbonaceous chondrites, providing strong constraints for modelling the formation conditions 72 and size-distribution of water-rich asteroids, especially in anticipation of the return of samples 73 of water-rich asteroids to Earth by the OSIRIS-REx and Hayabusa2 missions. 


\section{Introduction}

(20)

Dark C-type asteroids dominate the main-belt asteroid population and are genetically related to hydrous primitive CI and CM carbonaceous chondrites (Vilas \& Gaffey 1989; Hiroi et al. 1996; Vilas 1994; Burbine et al. 2002; Lauretta et al. 2019). CM chondrites are the most common water-rich meteorites, and CM-like matter represent an important fraction of exogenic clasts reported in other groups of meteorites, implying that CM parent bodies are widespread in the asteroid belt (Briani et al. 2012). CM chondrites are complex aggregates of high-temperature components formed in the disk and low-temperature secondary minerals formed during subsequent parent-body fluid circulations. The latter provide key constraints on the origin of water accreted by asteroids (Vacher et al. 2016; Piani et al. 2018) as well as their accretion and evolution histories (Young et al. 2003; Verdier-Paoletti et al. 2017; Vacher et al. 2017; Fujiya et al. 2015). CM chondrites are therefore important samples because they show varying degrees of alteration that can be easily estimated by their chemical alteration index (Rubin et al. 2007; Marrocchi et al. 2014; Vacher et al. 2018). Among secondary minerals, carbonates are of primary importance as they represent direct proxies of the asteroidal fluids from which they formed and can, in theory, be used to decipher their thermal evolution (Clayton \& Mayeda 1984). However, determining carbonate precipitation temperatures requires knowledge of the $\mathrm{O}$ isotopic compositions of their parental fluids, which itself requires knowledge of the carbonate precipitation temperatures, leading to a seemingly circular problem.

The temperature of $\mathrm{CM}$ carbonate precipitation remains largely underconstrained and proposed values cover a large range of temperatures. More generally, the sequence of formation of the different secondary phases (carbonates, serpentine) is poorly understood. Based on 'clumped-isotopes' and oxygen isotopic analyses, it has been proposed that CM 
carbonates could have precipitated at both low and medium temperatures, in the range of 0 $75^{\circ} \mathrm{C}$ (Clayton \& Mayeda 1984; Benedix et al. 2003; Guo \& Eiler 2007) and $50-350^{\circ} \mathrm{C}$ (Verdier-Paoletti et al. 2017; Alexander et al. 2015). However, these two different methodologies do not take account the petrographic relationship between carbonates and serpentine (Fuchs et al. 1973; Zolensky et al. 1997; Brearley 2006; Rubin et al. 2007; Vacher et al. 2018; Lee et al. 2013; 2014), which can constrain the evolution of the fluid over time. In addition, different types of carbonates are present in CM chondrites (Vacher et al. 2017; Lee et al. 2013; 2014) but no specific attention has been paid on their respective oxygen isotopic compositions. The objectives of this paper are thus to determine the oxygen isotopic composition of petrographically characterized carbonates in order to quantify the thermal evolution of hydrated asteroids. To do so, we surveyed a suite of different CM chondrites characterized by varying degrees of alteration: CM2.6/2.7 Maribo (van Kooten et al. 2018), CM2.5 Murchison (Rubin et al. 2007), CM2.4/2.7 Jbilet Winselwan (King et al. 2018) and CM2.0 Mukundpura (Rudraswami et al. 2018). Based on oxygen isotopic compositions of carbonates, we propose a new isotopic alteration model that reconciles petrographic observations and formation temperatures of $\mathrm{CM}$ carbonates.

\section{Material and methods}

\subsection{SEM imaging}

Calcite grains were located in carbon coated (i) polished sections of Murchison, Mukundpura and Jbilet Winselwan (samples provided by the Muséum National d'Histoire Naturelle in Paris) and (ii) thin section of Maribo (section provided by the Natural History Museum of Denmark in Copenhagen) using a Scanning Electron Microscope (SEM) JEOL JSM-6510 equipped with an energy dispersive X-ray detector (Bruker-AXS XFlash, silicon drift detector) at Centre de Recherches Pétrographiques et Géochimiques (CRPG, Nancy, 
124 France). Back-Scattered Electron (BSE) imaging were performed with a $3 \mathrm{nA}$ electron beam current operated at $15 \mathrm{kV}$.

126

\subsection{SIMS oxygen isotope analyses of calcite}

Calcite oxygen isotopic compositions were analysed using a CAMECA IMS 1270 E7 at CRPG laboratory. A Cs+ primary ion beam $(\sim 15 \times 10 \mu \mathrm{m}$ spot area) with a current of $\sim 5 \mathrm{nA}$ was used in order to collect ${ }^{16} \mathrm{O}^{-},{ }^{17} \mathrm{O}^{-}$and ${ }^{18} \mathrm{O}^{-}$secondary ions in multi-collection mode using three Faraday cups (L'2, FC2 and H1). Charge compensation was applied using a normalincidence electron gun. Mass Resolving Power $(M R P=M / \Delta M)$ was adjusted to $\sim 7000$ to resolve interference from ${ }^{16} \mathrm{OH}^{-}$on the ${ }^{17} \mathrm{O}^{-}$peak and achieve maximum flatness on the top of the ${ }^{16} \mathrm{O}^{-}$and ${ }^{18} \mathrm{O}^{-}$peaks (entrance and exit slits of FC2 were adjusted to $\sim 70 \mu \mathrm{m}$ and $\sim 170 \mu \mathrm{m}$, respectively). ${ }^{16} \mathrm{O}^{-}$and ${ }^{18} \mathrm{O}^{-}$secondary ions were collected on $\mathrm{L}$ '2 and $\mathrm{H} 1$, respectively (slit 1 , $\mathrm{MRP} \approx 2500)$. Pre-sputter on a large area $(\sim 20 \times 20 \mu \mathrm{m})$ was applied before each measurement during 60 s in order to remove carbon coating at the surface of the calcite grains. Acquisition time was set to $\sim 5 \mathrm{~s}$ and measurements were repeated over 30 cycles to achieve counting statistics $\sim 0.2 \%$ o $(1 \sigma)$ for $\delta^{18} \mathrm{O}$ and $\sim 0.3 \%$ for $\delta^{17} \mathrm{O}$. Isotope ratios $\left({ }^{17} \mathrm{O} /{ }^{16} \mathrm{O}\right.$ and $\left.{ }^{18} \mathrm{O} /{ }^{16} \mathrm{O}\right)$ are presented in per mil (\%o) relative to Standard Mean Ocean Water (SMOW):

$$
\delta^{\mathrm{x}} \mathrm{O}_{\text {SMOW }}(\%)=\left(\frac{{ }^{x} \mathrm{O} /{ }^{16} \mathrm{O}_{\text {sample }}}{{ }^{x} \mathrm{O} /{ }^{16} \mathrm{O}_{\text {SMOW }}}-1\right) \times 1000
$$

where $x$ represents ${ }^{17} \mathrm{O}$ or ${ }^{18} \mathrm{O}$ and SMOW the ratios of the SMOW standard. We measured two in-house terrestrial standards to define the Terrestrial Fractionation Line (TFL): (i) quartz $\left(\mathrm{SiO}_{2}\right)$ from Brazil $\left(\delta^{18} \mathrm{O}=9.6 \%\right.$, ${ }^{16} \mathrm{O}=2 \times 10^{9} \mathrm{cps}$ and $\left.{ }^{18} \mathrm{O}=4.2 \times 10^{6} \mathrm{cps}\right)$ and (ii) calcite $\left(\mathrm{CaCO}_{3}\right)$ from Mexico $\left(\delta^{18} \mathrm{O}=23.6 \%,{ }^{16} \mathrm{O}=2 \times 10^{9} \mathrm{cps}\right.$ and ${ }^{18} \mathrm{O}=4.2 \times 10^{6} \mathrm{cps} ; 0.03 \mathrm{wt} \%$ of $\mathrm{MgO}$ ). Instrumental Mass Fractionation (IMF) for calcite matrix was determined from our inhouse Mexican calcite standard at the beginning and end of each analytical session. IMF values for each sample analysis were then calculated by accounting for the linear deviation 
149 over the time of the IMF values. Typical measurement errors $(2 \sigma)$, accounting for errors on

150 each measurement and the external reproducibility of the standard, were estimated to be $151 \sim 0.5 \%$ for $\delta^{18} \mathrm{O}, \sim 0.6 \%$ for $\delta^{17} \mathrm{O}$, and $\sim 0.7 \%$ o for $\Delta^{17} \mathrm{O}$ (i.e., $\Delta^{17} \mathrm{O}=\delta^{17} \mathrm{O}-0.52 \times \delta^{18} \mathrm{O}$ ), 152 where $\Delta^{17} \mathrm{O}$ represents the departure from the TFL.

In the four $\mathrm{CM}$ chondrites surveyed in this work, calcite grains surrounded by Fe-S-

157 rich serpentine/tochilinite (hereafter T1 calcite; Fig. 1a) are ubiquitous whereas serpentine-

158 free polycrystalline calcite grains containing Fe-Ni sulfide inclusions (hereafter T2 calcite;

159 Fig. 1b) have only been observed in two sections (Jbilet Winselwan and Mukundpura). The O

160 isotopic compositions of $\mathrm{T} 1$ calcite grains measured herein vary widely, with $\delta^{18} \mathrm{O}$ values

161 ranging from 23.1 to $44.3 \%$, $\delta^{17} \mathrm{O}$ from 11.1 to $23.4 \%$ and $\Delta^{17} \mathrm{O}$ from -2.8 to $+1.8 \%$ (Figs $1 \mathrm{c}$

$162 \& \mathrm{~S} 1$, Table S1), whereas T2 calcite grains have homogeneous compositions with $\delta^{18} \mathrm{O}$ values

163 ranging from 12.6 to $18.4 \%$, $\delta^{17} \mathrm{O}$ from 4.2 to $8.1 \%$ and $\Delta^{17} \mathrm{O}$ from -4 to $-0.8 \%$ (Figs $1 \mathrm{c} \&$

164 S1, Table S2) 

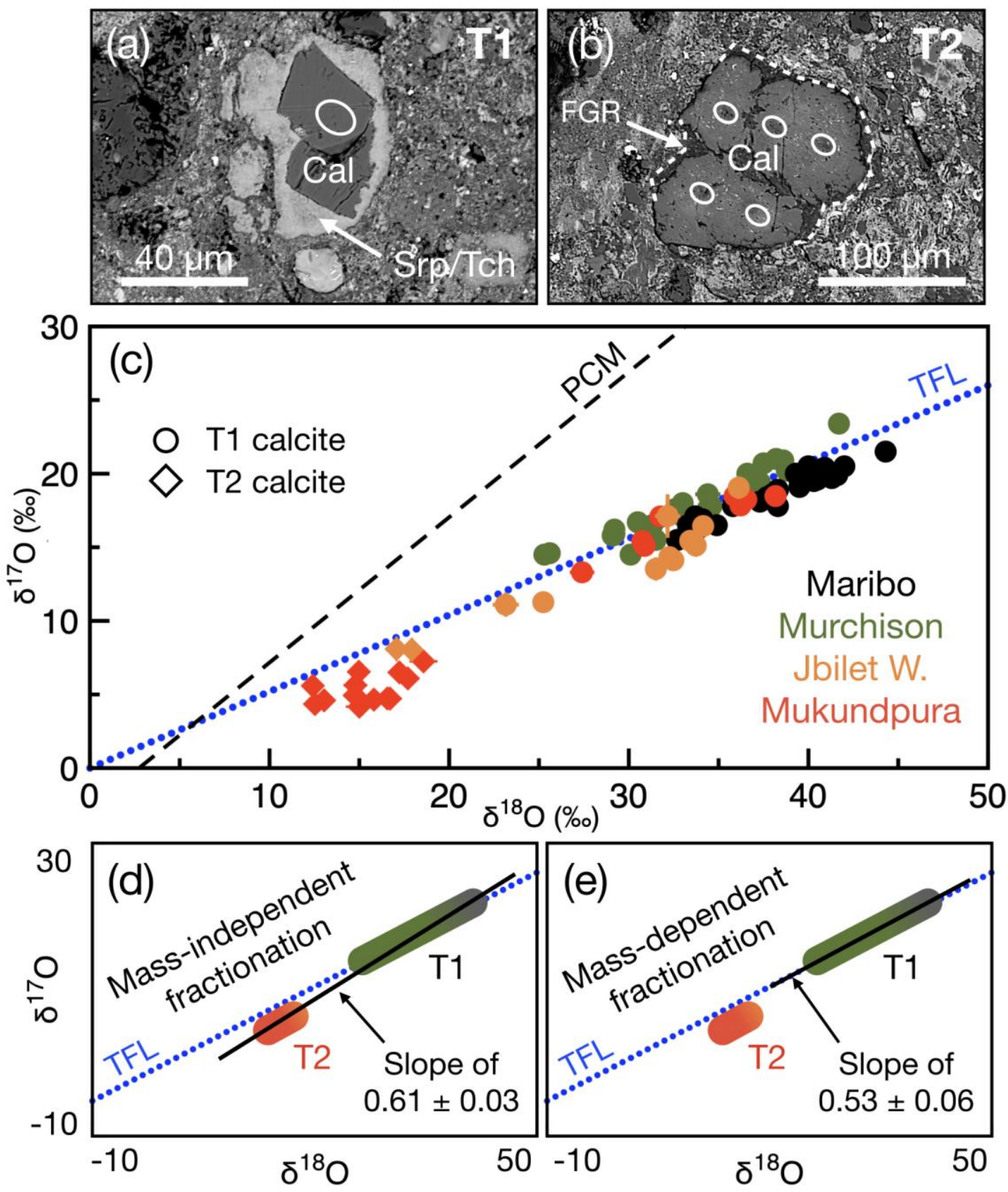

166 Fig. 1: Backscattered electron images of (a) a T1 calcite grain (Cal) surrounded by a Fe-S-rich

167 Serpentine/Tochilinite rim ( $\mathrm{Srp} / \mathrm{Tch})$ in the matrix of Murchison and (b) a T2 calcite grain that is free of 168 serpentine/tochilinite rim, but is instead surrounded by a rim of Fine-Grained Matrix (FGR; white dashed 169 line) in the matrix of Mukundpura. White circles represent the locations of SIMS analytical spots. (c) $\delta^{17} \mathrm{O}$ -

$170 \delta^{18} \mathrm{O}$ plot for T1 (circles) and T2 (diamonds) calcites from the CM chondrites Maribo (black), Murchison 171 (green), Jbilet Winselwan (orange) and Mukundpura (red) $\left(2 \sigma\right.$ errors). Schematic $\delta^{17} \mathrm{O}-\delta{ }^{18} \mathrm{O}$ diagrams 172 represent the linear correlations (black solid lines) obtained considering (d) T1 and T2 calcites, defining a 173 mass-independent trend with a slope of $0.61 \pm 0.03$ and (e) only T1 calcites, defining a mass-dependent 174 trend with a slope of $0.53 \pm 0.06$. TFL $=$ Terrestrial Fractionation Line $\left(\delta^{17} \mathrm{O}=0.52 \times \delta^{18} \mathrm{O}\right) ; \mathrm{PCM}=$ 175 Primary Chondrule Minerals line $\left(\delta^{17} \mathrm{O}=0.987 \times \delta^{18} \mathrm{O}-2.7\right)$. 
Together, T1 and T2 calcite grains define a mass-independent trend with $\delta^{17} \mathrm{O}=(0.61$

$179 \pm 0.03) \times \delta^{18} \mathrm{O}-(3.3 \pm 1.1)($ Fig. $1 \mathrm{c}-\mathrm{d})$ that is similar, within errors, to those commonly 180 reported in different CM chondrites (Vacher et al. 2018). As a first approximation, this trend suggests that the $\mathrm{O}$ isotopic compositions of $\mathrm{CM}$ carbonates is essentially controlled by variable degrees of isotopic exchanges between ${ }^{16} \mathrm{O}$-rich anhydrous silicates and a ${ }^{17,18} \mathrm{O}$-rich fluid (Fig. 1d; Verdier-Paoletti et al. 2017; Marrocchi et al. 2018). However, the O isotopic compositions of $\mathrm{T} 1$ calcites alone define a distinct trend with $\delta^{17} \mathrm{O}=(0.53 \pm 0.06) \times \delta^{18} \mathrm{O}-$ $(1.2 \pm 2.2)$ that is indistinguishable, within errors, from the TFL (i.e., $\Delta^{17} \mathrm{O}=-0.4 \pm 1.0$; Fig. 1e). Conversely, T2 calcites exhibit clustered $\delta^{17} \mathrm{O}-\delta^{18} \mathrm{O}$ values (Figs $1 \mathrm{c} \& \mathrm{~S} 1$, Table S2) with $\Delta^{17} \mathrm{O}=-2.6 \pm 1.0$, which artificially produce the aforementioned mass-independent trend when taken together with T1 calcites (Fig. 1d). This demonstrates that petrographic observations of carbonates are essential for understanding the $\mathrm{O}$ isotopic evolution of asteroidal fluids and the constraints they bear.

Based on mass-balance calculations, tentative attempts at estimating the $\mathrm{O}$ isotopic composition of primordial water accreted by $\mathrm{CM}$ chondrites have led to widely ranging and contrasted results due to assumptions on the $\mathrm{O}$ isotopic composition of the anhydrous

194 protolith and asteroidal thermal evolution $\left(\delta^{18} \mathrm{O}_{\text {fluid }}=16-55 \%\right.$, $\delta^{17} \mathrm{O}_{\text {fluid }}=9-35 \%$ and $195 \Delta \Delta^{17} \mathrm{O}_{\text {fluid }}=0.9-6.6 \%$; Verdier-Paoletti et al. 2017; Clayton \& Mayeda 1999; Fujiya 2018). However, these values correspond to the initial water composition and do not represent the oxygen isotopic compositions of fluids from which carbonates precipitated, which had Earth-

198 like compositions with $\Delta^{17} \mathrm{O} \approx 0 \%$ (Fig. 1c; Vacher et al. 2016; Verdier-Paoletti et al. 2017).

199 Quantitative estimates of the O isotopic compositions of the parental fluids of carbonates have 200 been obtained by $\mathrm{CO}_{2}$ clumped-isotope thermometry $\left(\Delta^{47}\right.$; Guo \& Eiler 2007), which 
corresponds to anomalous enrichments of mass 47 (i.e., ${ }^{13} \mathrm{C}^{18} \mathrm{O}^{16} \mathrm{O}$ ) in $\mathrm{CO}_{2}$ derived from $202 \mathrm{H}_{3} \mathrm{PO}_{4}$ digestion of carbonates (Ghosh et al. 2006). Based on measurements performed on the 203 CM chondrites Murchison and Murray, dominated by T1 calcites, Guo \& Eiler (2007) 204 estimated that the $\mathrm{O}$ isotopic compositions of their alteration fluids ranged from $\delta^{18} \mathrm{O}=2 \%$ 205 and $\Delta^{17} \mathrm{O}=-0.6 \%$ (hereafter $\mathrm{W}_{\min }$; Fig. 2a) to $\delta^{18} \mathrm{O}=6.8 \%$ and $\Delta^{17} \mathrm{O}=-0.5 \%$ (hereafter $206 \mathrm{~W}_{\max }$; Fig. 2a). Because these fluids experienced oxygen isotopic exchanges with the 207 anhydrous $\mathrm{CM}$ chondrite protolith $\left(\delta^{18} \mathrm{O}=-3.8 \%\right.$, $\delta^{17} \mathrm{O}=-6.5 \%$; Fig. S2), they define two 208 trends that delimit the possible O isotopic compositions of CM alteration fluids (blue shaded 209 area in Fig. 2a). Considering these extreme trends, the precipitation temperatures of each T1 210 calcite grain can be calculated according to the isotopic fractionation factor $\alpha$ (Watkins et al. 211 2013), which corresponds to the distance between the minimum and maximum trends and the 212 O isotopic compositions of carbonates in the three oxygen isotope diagram. This estimation 213 leads to respective minimum $\left(\mathrm{T}_{\min }\right)$ and maximum $\left(\mathrm{T}_{\max }\right)$ precipitation temperatures of $-9 \pm$ $21411^{\circ} \mathrm{C}$ and $5 \pm 14{ }^{\circ} \mathrm{C}$ for Maribo, $19 \pm 22{ }^{\circ} \mathrm{C}$ and $50 \pm 34{ }^{\circ} \mathrm{C}$ for Murchison, $15 \pm 21{ }^{\circ} \mathrm{C}$ and 33 $215 \pm 29{ }^{\circ} \mathrm{C}$ for Jbilet Winselwan and $12 \pm 17{ }^{\circ} \mathrm{C}$ and $34 \pm 22{ }^{\circ} \mathrm{C}$ for Mukundpura $(1 \sigma$; Table 1 216 and Fig. 3a). On average, this gives minimum and maximum precipitation temperatures for all $217 \mathrm{~T} 1$ calcites of $7 \pm 22{ }^{\circ} \mathrm{C}$ and $29 \pm 32{ }^{\circ} \mathrm{C}$, respectively $(1 \sigma)$. 


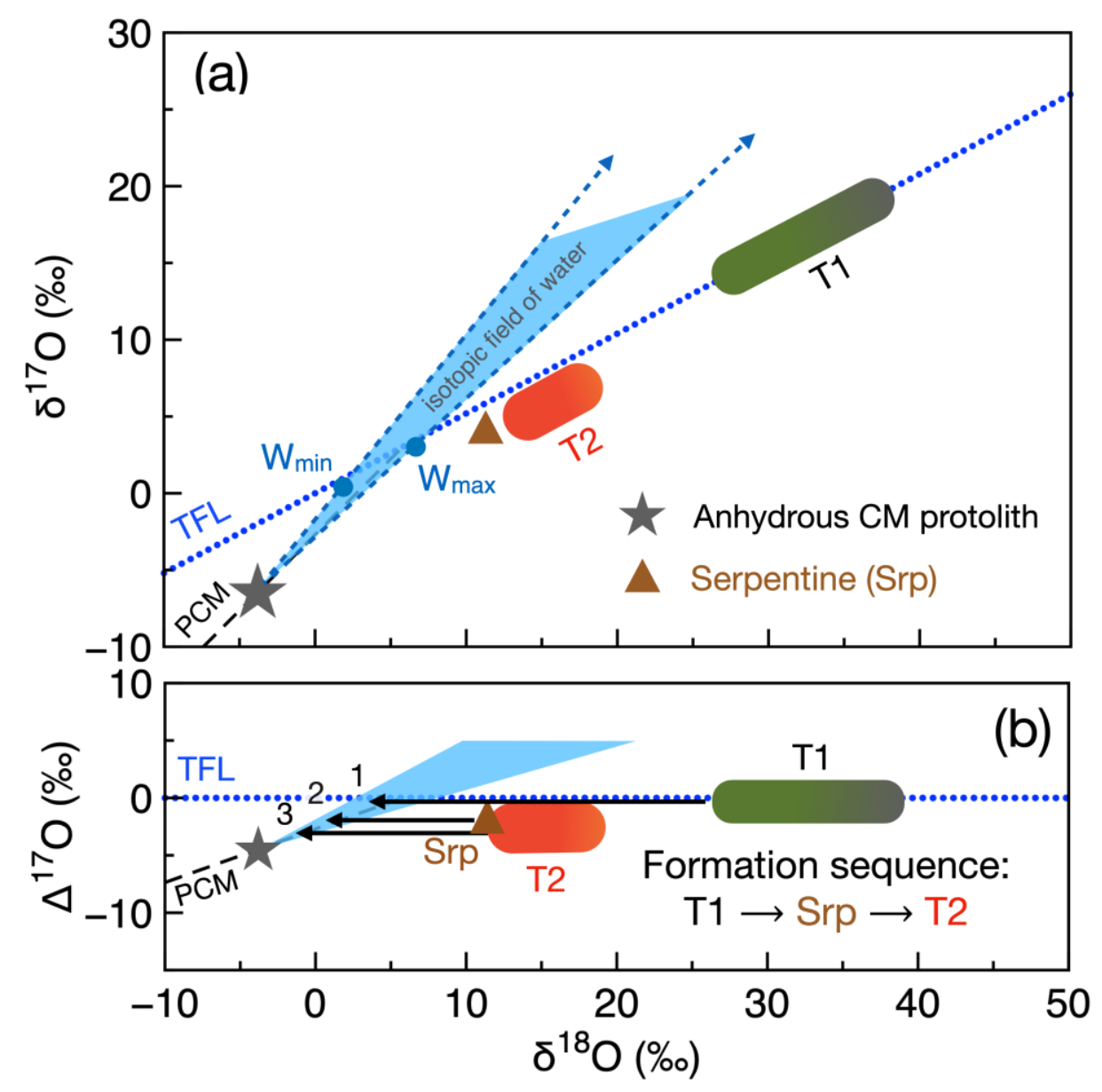

219 Fig. 2: (a) $\delta^{17} \mathrm{O}-\delta^{18} \mathrm{O}$ plot showing simplified ranges for $\mathrm{T} 1$ and $\mathrm{T} 2$ calcites, the mean bulk value of $\mathrm{CM}$ 220 serpentine (Srp, brown triangle) and the isotopic field of CM water (blue shaded area) as determined from 221 the isotopic equilibration (blue dashed lines) of the minimum $\left(\mathrm{W}_{\min }\right)$ and maximum $\left(\mathrm{W}_{\max }\right)$ compositions of 222 the parental water of $\mathrm{T} 1$ calcites (blue circles) with the anhydrous $\mathrm{CM}$ protolith (grey star; see 223 Supplementary Fig. S1 for details). (b) $\delta^{18} \mathrm{O}-\Delta^{17} \mathrm{O}$ plot showing the isotopic equilibration of CM water with 224 the anhydrous $\mathrm{CM}$ protolith. In this diagram, mass-dependent isotopic fractionations plot on a horizontal 225 line. The decrease of the mean $\Delta^{17} \mathrm{O}$ values of the secondary phases $\left(\Delta^{17} \mathrm{O}_{\mathrm{T} 1}=0.4 \%\right.$, $\Delta^{17} \mathrm{O}_{\mathrm{Srp}}=-2.2 \%$ and $226 \Delta \Delta^{17} \mathrm{O}_{\mathrm{T} 2}=-2.4 \%$; see Supplementary Tables $\mathrm{S} 1$ and $\mathrm{S} 2$ and Clayton \& Mayeda 1999) indicates the 227 following formation sequence: (1) T1 calcites, (2) serpentines and (3) T2 calcites. 
Table 1: Mean $O$ isotopic compositions of secondary phases and their calculated minimum $\left(\mathrm{T}_{\min }\right)$ and maximum $\left(\mathrm{T}_{\max }\right)$ formation temperatures (O’Neil et al., 1969). Uncertainties are $1 \sigma$.

231

\begin{tabular}{cccccccc}
\hline Meteorite & $\begin{array}{c}\text { Petrologic } \\
\text { subtype }\end{array}$ & $\begin{array}{c}\text { Secondary } \\
\text { phase }\end{array}$ & $\begin{array}{c}\text { Sample } \\
\text { number }\end{array}$ & $\begin{array}{c}\text { Mean } \mathbf{\delta}^{18} \mathbf{O} \\
(\mathbf{\%})\end{array}$ & $\begin{array}{c}\text { Mean } \Delta^{17} \mathbf{O} \\
(\mathbf{\%})\end{array}$ & $\begin{array}{c}\text { Mean Tmin } \\
\left({ }^{\circ} \mathbf{C}\right)\end{array}$ & $\begin{array}{c}\text { Mean Tmax } \\
\left({ }^{\circ} \mathbf{C}\right)\end{array}$ \\
\hline Maribo & $\mathrm{CM} 2.6 / 2.7^{\mathrm{a}}$ & T1 calcite & 25 & $38.3( \pm 3.1)$ & $-1.2( \pm 0.5)$ & $-9( \pm 11)$ & $5( \pm 14)$ \\
Murchison & $\mathrm{CM} 2.5^{\mathrm{b}}$ & T1 calcite & 24 & $33.7( \pm 4.5)$ & $0.4( \pm 0.8)$ & $19( \pm 22)$ & $50( \pm 34)$ \\
Jbilet & $\mathrm{CM} 2.4 / 2.7^{\mathrm{c}}$ & T1 calcite & 10 & $31.4( \pm 4.1)$ & $-1.6( \pm 1.2)$ & $15( \pm 21)$ & $33( \pm 29)$ \\
Winselwan & & T2 calcite & 2 & $17.5( \pm 0.6)$ & $-1( \pm 0.3)$ & $109( \pm 11)$ & $158( \pm 22)$ \\
Mukundpura & $\mathrm{CM} 2.0^{\mathrm{d}}$ & T1 calcite & 8 & $33.5( \pm 3.8)$ & $-0.7( \pm 0.6)$ & $12( \pm 17)$ & $34( \pm 22)$ \\
& & T2 calcite & 13 & $15.4( \pm 2)$ & $-2.6( \pm 1)$ & $110( \pm 32)$ & $139( \pm 55)$ \\
Bulk CM & - & Serpentine & 5 & $11.7( \pm 0.6)$ & $-2.2( \pm 0.3)$ & $28( \pm 8)^{\mathrm{f}}$ & $56( \pm 13)^{\mathrm{f}}$ \\
& & & & & & $73( \pm 7)^{\mathrm{g}}$ & $98( \pm 11)^{\mathrm{g}}$ \\
\hline
\end{tabular}

232 References: ${ }^{a}\left(\right.$ van Kooten et al. 2018); ${ }^{\text {b }}$ (Rubin et al. 2007); ' $\left(\right.$ King et al. 2018); ${ }^{\mathrm{d}}$ (Rudraswami et al. 2018); ${ }^{\mathrm{e}}$ (Clayton \& Mayeda 1999); ${ }^{\mathrm{f}}$ (Früh-Green et al. 1996); ${ }^{\mathrm{g}}$ (Zheng 1993)

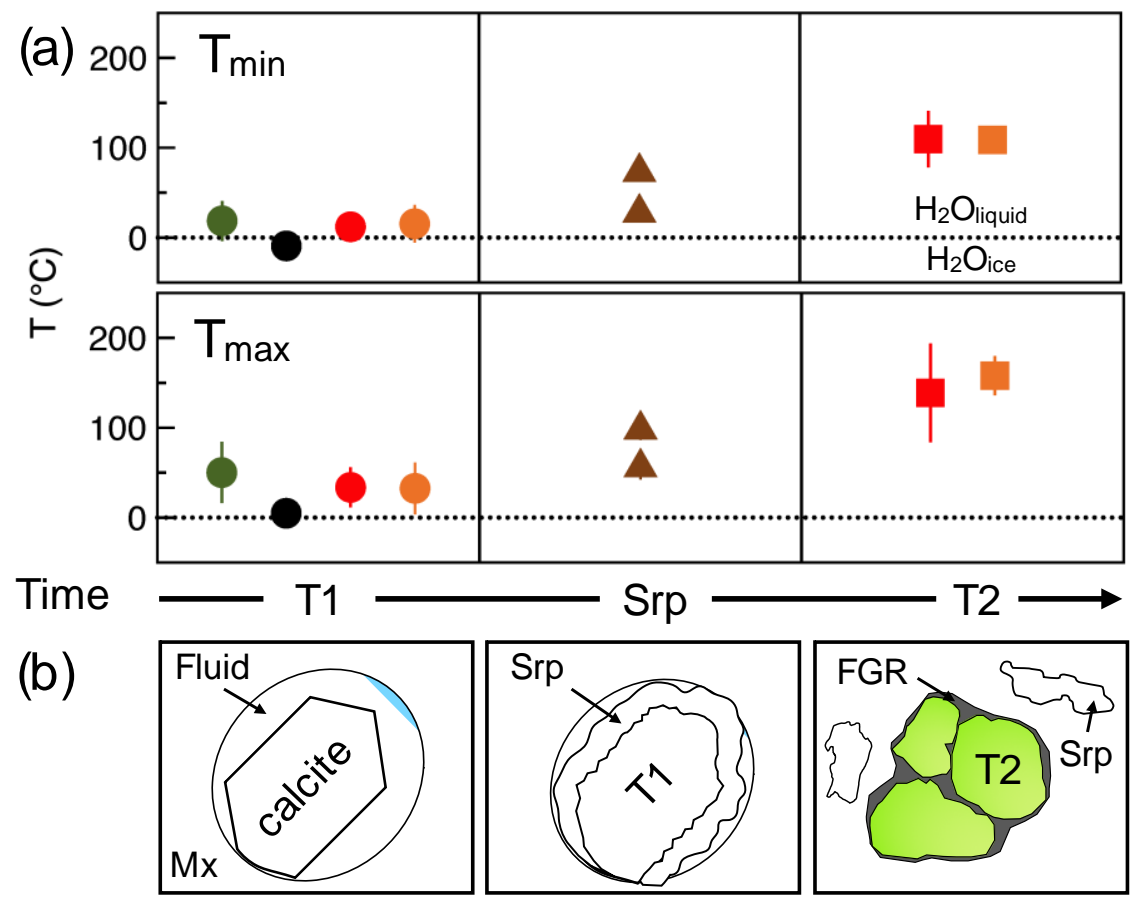

236 Fig. 3: (a) Minimum $\left(\mathrm{T}_{\min }\right)$ and maximum $\left(\mathrm{T}_{\max }\right)$ precipitation temperatures of $\mathrm{T} 1$ calcites (circles), 237 serpentines (brown triangles) and $\mathrm{T} 2$ calcites (diamonds) calculated as a function of their formation 238 sequence/time (errors are $1 \sigma$ ) using previously reported fractionation factors for calcite (O'Neil et al., 239 1969) and serpentine (Früh-Green et al. 1996; Zheng 1993). Colours are as in Fig. 1. (b) Schematic 240 representation of the formation sequence of (1) T1 calcite, (2) serpentine around T1 calcite and (3) T2 241 calcite, as deduced from petrographic observations and the mean $\Delta \Delta^{17} \mathrm{O}$ values of these three phases (see 242 Fig. 2c). 
The large range of $\delta^{17} \mathrm{O}-\delta^{18} \mathrm{O}$ values and constant $\Delta^{17} \mathrm{O}$ values observed in T1 calcites 245 (Fig. 1c-e, Table S1) imply that $\mathrm{T} 1$ calcites precipitated along a temperature gradient from 246 alteration fluids characterized by a fixed $\Delta^{17} \mathrm{O}$ value. On the other hand, T2 calcites (this study) and serpentine (Clayton \& Mayeda 1984) formed from a more ${ }^{16} \mathrm{O}$-rich fluid that resulted from protracted isotopic exchange with the ${ }^{16} \mathrm{O}$-rich anhydrous protolith and thus 249 evolved toward negative $\Delta^{17} \mathrm{O}$ values (Fig. 2b). Following the same methodology as for T1 250 calcites, we calculated the formation temperatures of $\mathrm{T} 2$ calcites to be significantly higher, with respective minimum and maximum temperatures being $109 \pm 11{ }^{\circ} \mathrm{C}$ and $158 \pm 22{ }^{\circ} \mathrm{C}$ for Jbilet Winselwan and $110 \pm 11^{\circ} \mathrm{C}$ and $139 \pm 55^{\circ} \mathrm{C}$ for Mukundpura $(1 \sigma$; Table 1 and Fig. 3a); respective average values are $109 \pm 29^{\circ} \mathrm{C}$ and $141^{\circ} \mathrm{C} \pm 52^{\circ} \mathrm{C}(1 \sigma)$. The same calculation

254 for bulk serpentine compositions ( $n=5$; Clayton \& Mayeda 1999) gives minimum and maximum formation temperatures of $28 \pm 8$ to $56 \pm 13{ }^{\circ} \mathrm{C}$ and $73 \pm 7$ to $98 \pm 11{ }^{\circ} \mathrm{C}$, respectively, depending of the fractionation factor considered (Früh-Green et al. 1996; Zheng 1993; 1 $\sigma$; Table 1 and Fig. 3a).

Our petrographic and isotopic approaches reveal that $\mathrm{T} 1$ calcites precipitated at lower 259 temperatures than serpentines and T2 calcites (Fig. 3a). These results support petrographic 260 observations suggesting that $\mathrm{T} 2$ calcites correspond to a later stage of alteration, as 261 highlighted by (i) the absence of serpentine rims and (ii) the existence of a fine-grained rim 262 (FGR) suggesting that they replaced chondrule silicates (Fig. 3b; Lee et al. 2014; Lindgren et 263 al. 2017). This implies that fluid circulation in CM parent bodies, and thus the formation of 264 CM secondary phases, occurred during a prograde thermal evolution (Figs. $2 b$ and $3 b$; Vacher 265 et al. 2019), with $\mathrm{T} 1$ calcites forming first at $T=-10$ to $+50{ }^{\circ} \mathrm{C}$, followed by the precipitation 266 of (Fe,S)-rich serpentine (mostly cronstedtite; Pignatelli et al. 2016; 2017) and tochilinite at $T$ $267=30-100{ }^{\circ} \mathrm{C}$ and finally $\mathrm{T} 2$ calcites at $T=110-160{ }^{\circ} \mathrm{C}$ (Fig. 3a, Table 1$)$. 
According to X-ray diffraction studies (Howard et al. 2011; 2009), serpentine represent the most abundant mineral in $\mathrm{CM}$ chondrites (75 vol\% in average). Their formations (posterior to that of $\mathrm{T} 1$ calcites) would thus affect the isotopic evolution of the alteration fluids, leading to a slight shift toward ${ }^{16} \mathrm{O}$-enriched values. As this isotopic shift is not taken into account in our model, this implies that the precipitation temperatures estimated for $\mathrm{T} 2$ calcites (Fig. 3a, Table 1) should be considered as maximum values. However, as the fractionation factor $\alpha$ is significantly lower for serpentine-water than for calcite-water (i.e., $1000 \ln \alpha_{\text {serpentine-water }}=6.3$ vs $1000 \ln \alpha_{\text {calcite-water }}=17.1$ at $100^{\circ} \mathrm{C}$; O’Neil et al. 1969 ; FruhGreen et al., 1996), this approximation does not affect our main conclusions that $\mathrm{T} 1$ calcites precipitated at lower temperature than $\mathrm{T} 2$ calcites.

As the uncertainties on the $\mathrm{O}$ isotopic compositions of primordial water accreted by $\mathrm{CM}$ chondrites could also affect our conclusions, we tested our results with different initial $\mathrm{O}$ isotopic compositions (Fig. 4). According to the currently favoured self-shielding model, 281 primordial water is hypothesized to have had a large ${ }^{17,18} \mathrm{O}$ enrichment (i.e., $\delta^{17} \mathrm{O}=\delta^{18} \mathrm{O} \approx$ $282180 \%$; Sakamoto et al. 2007) plotting on a line of slope 1 in a three oxygen isotope diagram. 283 However, mass balance calculations performed on the $\mathrm{O}$ isotopic compositions of $\mathrm{CM}$ chondrites at bulk and mineral scales suggest more modest enrichments in the heavy oxygen isotopes with $\delta^{17} \mathrm{O}=35 \pm 9 \%$ and $\delta^{18} \mathrm{O}=55 \pm 13 \%$ (Fujiya 2018). Hence, we tested our results by using primordial $\mathrm{CM}$ water $\mathrm{O}$ isotopic compositions corresponding to (i) a 287 composition intermediate between $\mathrm{W}_{\min }$ and $\mathrm{W}_{\max }\left(\mathrm{W}_{\mathrm{int}}\right)$ and (ii) the values proposed by 288 Fujiya (2018) ( $\mathrm{W}_{\mathrm{F}}$, Fig. 4a). Isotopic exchange between these fluid compositions and the anhydrous CM protolith (Marrocchi et al. 2018) thus defines two other lines on the $\delta^{17,18} \mathrm{O}$

290 diagram ( $b$ and $\mathrm{d}$ in Fig. 4a, with lines a and c corresponding to the trends defined by $\mathrm{W}_{\min }$ 291 and $\mathrm{W}_{\max }$, respectively) from which the precipitation temperatures of $\mathrm{T} 1$ and $\mathrm{T} 2$ calcites can 292 be calculated according to the fractionation factor $\alpha$ (Watkins et al. 2013). The results for 
293 Jbilet Winselwan and Mukundpura (the only meteorites containing T2 calcites in this study) 294 systematically show that T2 calcites precipitated at higher temperatures than T1 calcites (Fig. $2954 b-c)$, regardless of the oxygen isotopic composition used for primordial water. Depending 296 on the isotopic trend considered (a, b, c or d in Fig. 4a), the average precipitation temperatures 297 of T1 calcites range from 10 to $100{ }^{\circ} \mathrm{C}$, whereas $\mathrm{T} 2$ calcites formed between 110 and $245^{\circ} \mathrm{C}$ 298 (Fig. 4b-c). We note that the absolute temperatures at which secondary phases formed is 299 directly affected by the oxygen isotopic composition of primordial chondritic water, whose 300 precise determination is thus fundamental to better quantifying the thermal evolution of 301 hydrated asteroids. 

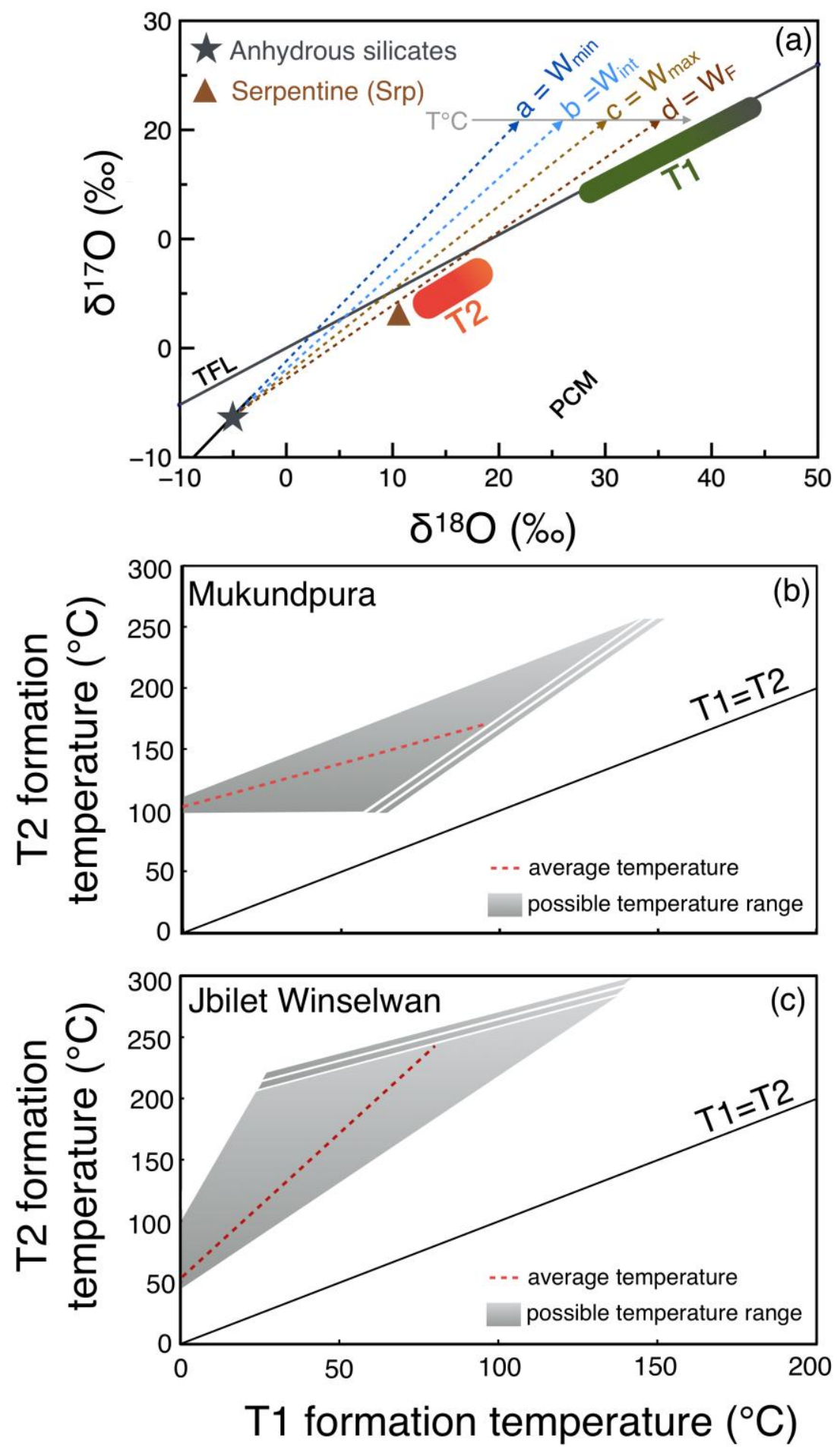

303 Fig. 4: (a) $\delta^{17} \mathrm{O}-\delta^{18} \mathrm{O}$ plot showing the four trends (see text) used to calculate the influence of the initial 304 oxygen isotopic composition of primordial water on the thermal path interpreted for water-rich asteroids. $305(\mathrm{~b}, \mathrm{c}) \delta^{17} \mathrm{O}-\delta^{18} \mathrm{O}$ plots showing the results of the model for Mukundpura and Jbilet Winselwan, respectively.

306 In both cases, the average formation temperatures of $\mathrm{T} 2$ calcites are systematically higher than those 307 estimated for $\mathrm{T} 1$ calcites (red dashed lines), even when accounting for variability in the $\delta^{17} \mathrm{O}$ and $\delta^{18} \mathrm{O}$ 308 values of calcites in Jbilet Winselwan and Mukundpura (grey triangles). 
Another possible source of uncertainty in estimating precipitation temperatures arises

311 if $\mathrm{T} 1$ calcites experienced post-precipitation isotopic reequilibration, especially if CM

312 chondrites experienced peak temperatures as high as $250{ }^{\circ} \mathrm{C}$. However, this appears unlikely

313 as T1 calcites systematically show mass-dependent oxygen isotopic variations

314 (Supplementary Fig. S3), whereas isotopic exchange between initial water and anhydrous

315 silicates during reequilibration would have induced $\Delta^{17} \mathrm{O}$ variations (Fig. 2a). In addition,

316 according to the values of oxygen self-diffusion in calcite (Anderson 2007; Farver 1994), 1-

$31710^{4} \mathrm{Gyr}$ are required to isotopically reequilibrate calcite grains of $5 \mu \mathrm{m}$ in size at temperatures

$318 \leq 200{ }^{\circ} \mathrm{C}$ (Fig. S3). Such results thus strengthen our conclusion that hydrated asteroids

319 experienced a prograde thermal evolution with T1 calcites precipitating first, followed by

320 serpentine and then T2 calcites.

By taking into account the petrographic type of carbonates, our hydrothermal temperature estimates for $\mathrm{CM}$ chondrites are higher than previously proposed (Clayton \& Mayeda 1984; Benedix et al. 2003; Guo \& Eiler 2007) but remain low ( $\left.<250{ }^{\circ} \mathrm{C}\right)$ compared to the peak of thermal metamorphism experienced by other groups of carbonaceous chondrites, such as $\mathrm{CO}$ or $\mathrm{CV}$ chondrites (up to $500-600{ }^{\circ} \mathrm{C}$; Bonal et al. 2007; Busemann et al. 2007; Cody et al. 2008; Ganino \& Libourel 2017). This implies the relatively late accretion of water-rich asteroids in the protoplanetary disk, as water-poor asteroids that accreted earlier experienced significantly higher temperatures due to the radioactive decay of ${ }^{26} \mathrm{Al}$. Based on $\varepsilon^{54} \mathrm{Cr}$ anomalies, it has been proposed than $\mathrm{CM}$ chondrites accreted $\sim 3.7-5.0 \mathrm{Myr}$ after the

330 formation of CV calcium-aluminium-rich inclusions (CAIs; Fujiya et al. 2012; Doyle et al. 331 2015; Sugiura \& Fujiya 2014), after a five-fold decrease in the abundance of ${ }^{26} \mathrm{Al}$, whereas $332 \mathrm{CO}$ and $\mathrm{CV}$ chondrites accreted $\sim 2.1-2.4$ and $\sim 2.4-2.6 \mathrm{Myr}$ after CV CAIs, respectively 333 (Doyle et al. 2015). Interestingly, recent spectral data provided by the Osiris-REx and 334 Hayabusa2 asteroid sample return missions suggest that C-type asteroid Ryugu has 
experienced more heating than B-type asteroid Bennu (Hamilton et al. 2019; Kitazato et al., 2019). Although late shock heating could have induced such features, their different thermal history could also be the result of distinct accretion ages. The returned samples from OsirisREx and Hayabusa2 in the near future will likely contain hydrated minerals (Kitazato et al. 2019; Lauretta et al. 2019) whose in-situ isotopic analyses would provide information on the thermal alteration processes and formation histories of asteroids Ryugu and Bennu.

\section{Conclusions} chondrites) to quantitively estimate the thermal evolution of hydrated asteroids. Based on our isotopic results, we propose a new isotopic model that reconciles formation temperatures and petrographic observations of secondary minerals whose isotopic compositions recorded a gradual increase of the temperature (up to $250^{\circ} \mathrm{C}$ ) during a prograde evolution of the temperature, regardless the oxygen isotopic composition of the initial water. These results are fundamental because they imply that hydrated asteroids accreted relatively late in the protoplanetary disk, as their earlier accretion would have led to higher alteration temperatures due to higher concentrations of radioactive ${ }^{26} \mathrm{Al}$. Although more precise radioactive dating and numerical modelling are required, our study provides a key method to quantitatively estimate the respective thermal histories of the asteroids Bennu (Lauretta et al. 2019) and Ryugu (Sugita et al. 2019; Watanabe et al. 2019) upon the return of samples to Earth.

\section{Acknowledgments}

362 with the isotopic measurements. Laurette Piani is thanked for helpful scientific discussions. 
363 The Muséum National d'Histoire Naturelle (Paris) and The Natural History Museum of 364 Denmark (Copenhagen) are also thanked for providing samples of Mukundpura and sections 365 of Maribo chondrites. We thank Pr. Frederic Rasio for his editorial handling and the 366 anonymous reviewer for his comments that contributed to improve the quality of the 367 manuscript. This research was funded by l'Agence Nationale de la Recherche through grant 368 ANR-587 14-CE33-0002-01 SAPINS (PI Yves Marrocchi). This is CRPG contribution \#2714. 

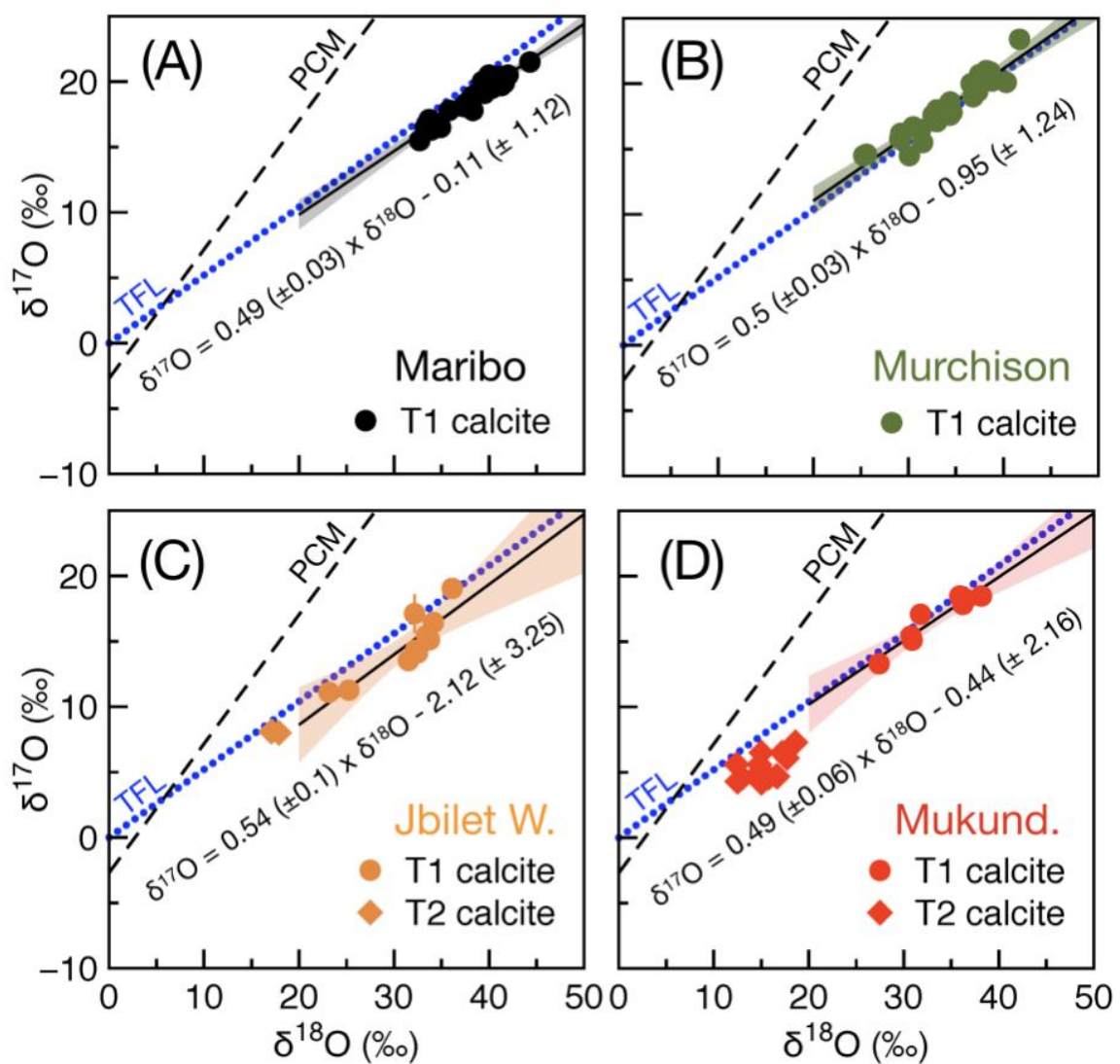

Fig. S1: $\delta^{17} \mathrm{O}-\delta^{18} \mathrm{O}$ plots showing the mass-dependent trends (black solid line) defined by T1 calcites (circles) for each CM chondrite: (a) Maribo, (b) Murchison, (c) Jbilet Winselwan and (d) Mukundpura. Shaded areas represent the $95 \%$ confidence interval for each slope. T2 calcites (diamonds) are also shown for Jbilet Winselwan (c) and Mukundpura (d), the only chondrites studied herein containing T2 calcites. Errors are $2 \sigma$. 


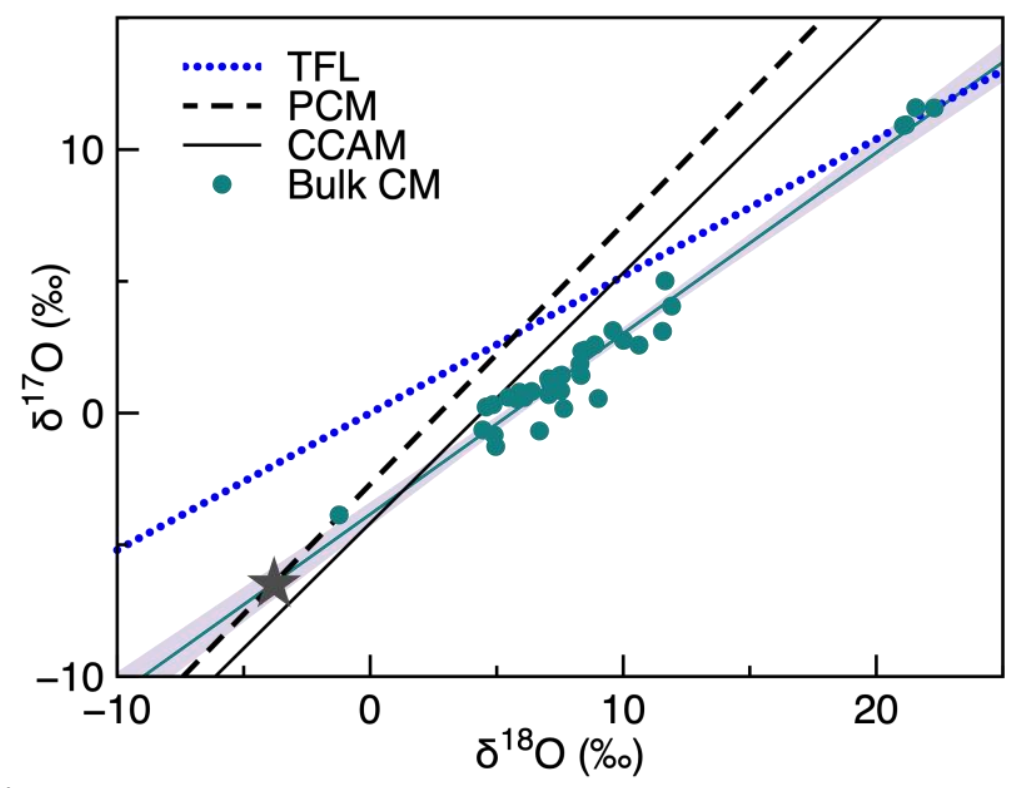

383
Fig. S2: $\delta^{17} \mathrm{O}-\delta^{18} \mathrm{O}$ plot showing the $\mathrm{O}$ isotopic composition of the anhydrous $\mathrm{CM}$ protolith (i.e., the theoretical anhydrous bulk $\mathrm{CM}$ composition: $\delta^{18} \mathrm{O}=-3.8 \%$ and $\delta^{17} \mathrm{O}=-6.5 \%$; grey star) determined from the linear correlation of the CM bulk composition (green circle(Clayton \& Mayeda 1999; Hewins et al. 2014)). The anhydrous $\mathrm{CM}$ protolith corresponds to the intercept between the bulk $\mathrm{CM}$ trend $\left(\delta^{17} \mathrm{O}=0.69\right.$ $\left.\times \delta^{18} \mathrm{O}-3.8 ; n=36\right)$ and the PCM line $\left(\delta^{17} \mathrm{O}=0.987 \times \delta^{18} \mathrm{O}-2.7\right.$; (Ushikubo et al. 2012)). CCAM: Carbonaceous chondrite anhydrous minerals line. 


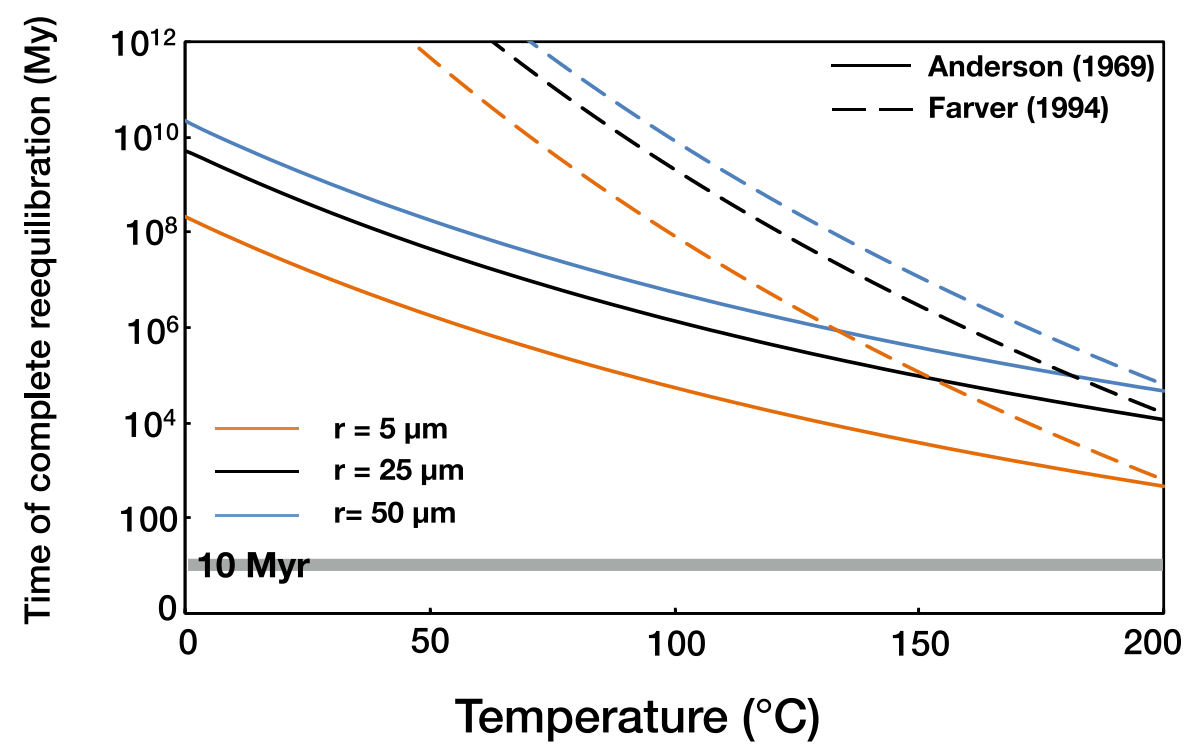

Fig. S3: Time (Myr) required for the complete reequilibration of early precipitated $\mathrm{T} 1$ calcite as a function of grain size (radius) and temperature, calculated using oxygen self-diffusion parameters for calcite (Farver 1994). The grey shaded region at $10 \mathrm{Myr}$ corresponds to the duration estimated for fluid circulations in asteroidal parent bodies (Fujiya et al. 2012; Doyle et al. 2015; Petitat et al. 2011).

405

406

407

408

409

410

411

412

413

414

415

416

417

418

419

420

421

422

423 
Table S1: Oxygen isotopic compositions of T1 calcite grains in the CM chondrites Maribo, Murchison, Jbilet Winselwan and Mukundpura.

\begin{tabular}{|c|c|c|c|c|c|c|}
\hline$\#$ & $\delta^{18} O$ & $2 \sigma$ & $\delta^{17} O$ & $2 \sigma$ & $\Delta^{17} \mathbf{O}$ & $2 \sigma$ \\
\hline $\mathrm{CC} 7$ & 32.7 & 0.3 & 15.5 & 0.5 & -1.5 & 0.8 \\
\hline CC21-1 & 33.3 & 0.3 & 16.5 & 0.8 & -0.8 & 1 \\
\hline CC21-2 & 33.9 & 0.3 & 16.3 & 0.7 & -1.3 & 0.9 \\
\hline CC22 & 33.7 & 0.3 & 17.1 & 0.5 & -0.4 & 0.8 \\
\hline CC20 & 34.1 & 0.4 & 16.9 & 0.6 & -0.9 & 0.9 \\
\hline $\mathrm{CC} 27$ & 34.9 & 0.2 & 16.5 & 0.5 & -1.7 & 0.7 \\
\hline CC30 & 35.8 & 0.3 & 17.8 & 0.5 & -0.8 & 0.7 \\
\hline CC10 & 37.3 & 0.6 & 18.1 & 0.6 & -1.3 & 1 \\
\hline CC11 & 37.7 & 0.2 & 18.4 & 0.5 & -1.3 & 0.7 \\
\hline CC4-2 & 38 & 0.3 & 18.6 & 0.5 & -1.1 & 0.8 \\
\hline CC4-1 & 41.6 & 0.3 & 19.9 & 0.5 & -1.7 & 0.7 \\
\hline CC5 & 38.3 & 0.3 & 18.9 & 0.6 & -1.1 & 0.8 \\
\hline CC17 & 38.3 & 0.3 & 17.8 & 0.6 & -2.2 & 0.8 \\
\hline CC9 & 39.3 & 0.3 & 20 & 0.5 & -0.4 & 0.8 \\
\hline CC33 & 39.5 & 0.3 & 19.1 & 0.5 & -1.4 & 0.5 \\
\hline CC32 & 39.5 & 0.3 & 19.6 & 0.7 & -0.9 & 0.9 \\
\hline CC13 & 40 & 0.5 & 20.5 & 0.6 & -0.3 & 1 \\
\hline CC3 & 40.2 & 0.3 & 20 & 0.6 & -0.9 & 0.7 \\
\hline CC28 & 40.3 & 0.2 & 19.5 & 0.6 & -1.4 & 0.8 \\
\hline CC29 & 40.5 & 0.3 & 19.6 & 0.6 & -1.5 & 0.6 \\
\hline CC12 & 40.6 & 0.3 & 19.7 & 0.5 & -1.4 & 0.8 \\
\hline CC15 & 40.9 & 0.4 & 20.4 & 0.5 & -0.9 & 0.6 \\
\hline $\mathrm{CC} 2$ & 41.3 & 0.3 & 19.7 & 0.5 & -1.7 & 0.8 \\
\hline CC18 & 42 & 0.3 & 20.5 & 0.5 & -1.4 & 0.8 \\
\hline $\mathrm{CC} 1$ & 44.3 & 0.3 & 21.5 & 0.6 & -1.5 & 0.8 \\
\hline Mean & 38.3 & & 18.7 & & -1.2 & \\
\hline StDev & 3.1 & & 1.6 & & 0.5 & \\
\hline CC-7-2 & 25.3 & 0.2 & 14.5 & 0.4 & 1.3 & 0.3 \\
\hline CC-7-3 & 25.6 & 0.2 & 14.6 & 0.4 & 1.3 & 0.4 \\
\hline A-CC-5-2 & 29.1 & 0.5 & 15.8 & 0.4 & 0.7 & 0.6 \\
\hline A-CC-5-3 & 36.6 & 0.2 & 20 & 0.3 & 1 & 0.3 \\
\hline A-CC-8-2 & 29.2 & 0.6 & 15.9 & 0.6 & 0.7 & 0.7 \\
\hline CC-1-2 & 29.2 & 0.3 & 16.2 & 0.4 & 1 & 0.4 \\
\hline A-CC-11-1 & 30.1 & 0.5 & 14.5 & 0.6 & -1.1 & 0.7 \\
\hline CC-6 & 30.5 & 0.3 & 16.7 & 0.3 & 0.8 & 0.4 \\
\hline A-CC-3-2 & 31.3 & 0.9 & 16.5 & 0.8 & 0.3 & 1.1 \\
\hline A-CC-3-1 & 34.4 & 0.7 & 18.6 & 0.7 & 0.7 & 0.9 \\
\hline A-CC-10 & 31.5 & 0.9 & 15.5 & 0.6 & -0.9 & 1.0 \\
\hline A-CC-13 & 32.6 & 0.3 & 17.6 & 0.3 & 0.7 & 0.4 \\
\hline A-CC-7 & 33 & 0.5 & 17.1 & 0.6 & 0 & 0.7 \\
\hline CC-18 & 33 & 0.2 & 18 & 0.3 & 0.9 & 0.3 \\
\hline A-CC-2-2 & 34.4 & 0.6 & 17.6 & 0.6 & -0.3 & 0.8 \\
\hline CC-3 & 34.6 & 0.3 & 17.8 & 0.4 & -0.2 & 0.4 \\
\hline $\mathrm{CC}-2$ & 36.8 & 0.2 & 19 & 0.3 & -0.1 & 0.3 \\
\hline $\mathrm{CC}-5$ & 37.3 & 0.6 & 19.4 & 0.6 & 0 & 0.8 \\
\hline CC-10 & 37.5 & 0.2 & 20.7 & 0.3 & 1.2 & 0.3 \\
\hline CC-12 & 38.2 & 0.3 & 21 & 0.3 & 1.1 & 0.3 \\
\hline $\mathrm{A}-\mathrm{CC}-1$ & 38.6 & 0.6 & 20.9 & 0.6 & 0.8 & 0.8 \\
\hline CC-11 & 38.8 & 0.3 & 20.2 & 0.3 & 0 & 0.4 \\
\hline CC-9 & 40.3 & 0.3 & 20.1 & 0.3 & -0.8 & 0.4 \\
\hline CC-8 & 41.7 & 0.4 & 23.4 & 0.3 & 1.8 & 0.4 \\
\hline Mean & 33.7 & & 18 & & 0.4 & \\
\hline StDev & 4.5 & & 2.4 & & 0.8 & \\
\hline CC-6 & 23.1 & 0.7 & 11.1 & 0.8 & -0.9 & 1.0 \\
\hline CC-5 & 25.2 & 0.4 & 11.3 & 0.7 & -1.9 & 0.7 \\
\hline CC-11 & 31.5 & 0.5 & 13.5 & 0.8 & -2.8 & 0.9 \\
\hline
\end{tabular}




\begin{tabular}{ccccccc} 
CC-3 & 32.2 & 0.7 & 17.1 & 1.5 & 0.4 & 1.6 \\
CC-2 & 32.3 & 0.6 & 14.3 & 0.7 & -2.4 & 0.8 \\
CC-7 & 32.5 & 0.5 & 14.1 & 0.7 & -2.8 & 0.7 \\
CC-9 & 33.4 & 0.5 & 15.4 & 0.7 & -1.9 & 0.7 \\
CC-8 & 33.7 & 0.5 & 15.1 & 0.8 & -2.4 & 0.8 \\
CC-1 & 34.1 & 0.5 & 16.4 & 0.7 & -1.3 & 0.8 \\
CC-10 & 36.1 & 0.5 & 19.1 & 0.8 & 0.3 & 0.8 \\
Mean & $\mathbf{3 1 . 4}$ & & $\mathbf{1 4 . 8}$ & & $\mathbf{- 1 . 6}$ & \\
StDev & 4.1 & & 2.5 & & 1.2 & \\
\hline CC15 & 27.4 & 0.7 & 13.3 & 0.4 & -0.9 & 0.6 \\
CC13 & 30.8 & 0.6 & 15.4 & 0.4 & -0.6 & 0.6 \\
CC14 & 30.9 & 0.6 & 15.1 & 0.4 & -1 & 0.6 \\
CC1 & 31.8 & 0.5 & 17.1 & 0.4 & 0.6 & 0.5 \\
CC12 & 35.9 & 0.6 & 18.5 & 0.4 & -0.2 & 0.6 \\
CC8-1 & 36.2 & 0.6 & 17.8 & 0.4 & -1 & 0.6 \\
CC11 & 36.5 & 0.6 & 18.2 & 0.4 & -0.8 & 0.6 \\
CC7-1 & 38.2 & 0.6 & 18.5 & 0.4 & -1.4 & 0.6 \\
Mean & $\mathbf{3 3 . 5}$ & & $\mathbf{1 6 . 7}$ & & $\mathbf{- 0 . 7}$ & \\
StDev & 3.8 & & 1.9 & & 0.6 & \\
\hline
\end{tabular}


Table S2: Oxygen isotopic compositions of T2 calcite grains in the CM chondrites Jbilet Winselwan and Mukundpura.

\begin{tabular}{ccccccc}
\hline$\#$ & $\boldsymbol{\delta}^{\mathbf{1 8}} \mathbf{O}$ & $\mathbf{2 \sigma}$ & $\boldsymbol{\delta}^{\mathbf{1 7}} \mathbf{O}$ & $\mathbf{2 \sigma}$ & $\Delta^{\mathbf{1 7}} \mathbf{O}$ & $\mathbf{2 \sigma}$ \\
\hline CC15 & 17.1 & 0.4 & 8.1 & 0.9 & -0.8 & 0.9 \\
CC14 & 17.9 & 0.5 & 8 & 0.8 & -1.3 & 0.0 \\
Mean & $\mathbf{1 7 . 5}$ & & $\mathbf{8 . 1}$ & & $\mathbf{- 1}$ & \\
StDev & 0.6 & & 0 & & 0.3 & \\
\hline CC3-1 & 12.4 & 0.6 & 5.6 & 0.3 & -0.9 & 0.5 \\
CC3-4 & 12.5 & 0.6 & 4.3 & 0.4 & -2.2 & 0.6 \\
CC3-3 & 13 & 0.6 & 4.6 & 0.4 & -2.2 & 0.6 \\
CC3-2 & 15 & 0.5 & 6.5 & 0.4 & -1.2 & 0.6 \\
CC17-1 & 14.7 & 0.6 & 4.9 & 0.4 & -2.7 & 0.6 \\
CC17-2 & 17.7 & 0.6 & 6.1 & 0.4 & -3.1 & 0.6 \\
CC5-1 & 14.8 & 0.7 & 5.6 & 0.4 & -2 & 0.6 \\
CC5-5 & 15 & 0.8 & 4.2 & 0.5 & -3.6 & 0.7 \\
CC5-3 & 15.8 & 0.7 & 4.6 & 0.4 & -3.6 & 0.7 \\
CC5-2 & 16.6 & 0.5 & 4.7 & 0.4 & -3.9 & 0.5 \\
CC5-4 & 16.7 & 0.6 & 4.7 & 0.5 & -4 & 0.6 \\
CC6-1 & 17.2 & 0.6 & 6.5 & 0.4 & -2.5 & 0.6 \\
CC9 & 18.6 & 0.8 & 7.3 & 0.4 & -2.4 & 0.7 \\
Mean & $\mathbf{1 5 . 4}$ & & $\mathbf{5 . 4}$ & & $\mathbf{- 2 . 6}$ & \\
StDev & 2.0 & & 1.0 & & 1.0 & \\
\hline
\end{tabular}




\section{References}

Alexander, C. M. O., Bowden, R., Fogel, M. L., \& Howard, K. T. 2015, MPS, 50, 810. Anderson, T. F. 1969, J. Geophys. Res., 74, 3918.

Benedix, G. K., Leshin, L. A., Farquhar, J., Jackson, T., et al 2003, GCA, 67, 1577.

Bonal, L., Bourot-Denise, M., Quirico, E., et al. 2007, GCA, 71, 1605.

Brearley, A. J. 2006, MESS II, 943, 587.

Briani, G., Gounelle, M., Bourot-Denise, M., \& Zolensky, M. E. 2012, MPS, 47, 880.

Burbine, T., McCoy, T., Meibom, A., Gladman, B., \& Keil, K. 2002, Asteroids III, 1, 653.

Busemann, H., Alexander, C. M. O’D., \& Nittler, L. R. 2007, MPS, 42, 1387.

Clayton, R. N., \& Mayeda, T. K. 1984, EPSL, 67, 151.

Clayton, R. N., \& Mayeda, T. K. 1999, GCA, 63, 2089.

Cody, G. D., Alexander, C. M. O’D., Yabuta, H., et al. 2008, EPSL, 272, 446.

Doyle, P.M., Jogo, K., Nagashima, K., et al. 2015, Nat Comms 6, 7444.

Farver, J.R. 1994, EPSL, 121, 575.

Früh-Green, G. L., Plas, A, Lécuyer C. 1996, 14. Proc. Ocean Drilling. Programm. 147, 255.

Fuchs, L. H., Olsen, E., \& Jensen, K. J. 1973, Smithsonian Contr. Earth Sci., 10, 1.

Fujiya, W., Sugiura, N., Hotta, H., et al. 2012, Nat Comms, 3, 627.

Fujiya, W., Sugiura, N., Marrocchi, Y., et al. 2015, GCA, 161, 101.

Fujiya, W. 2018, EPSL, 481, 264.

Ganino, C., Libourel, G. 2017 Nat Comms, 8, 261.

Ghosh, P., Adkins, J., Affek, H., et al. 2006, GCA, 70, 1349.

Guo, W., \& Eiler, J. M. 2007, GCA, 71, 5565.

Hamilton, V. E., Simon, A. A., Christensen, P. R., et al. 2019, Nat. Astron., 3, 332.

Hewins, R. H., Bourot-Denise, M., Zanda, B., et al. 2014, GCA, 124, 190.

Hiroi, T., Pieters, C. M., Zolensky, M. E., \& Lipschutz, M. E. 1996, MPS, 31, 321.

Howard, K. T., Benedix, G. K., Bland, P. A., \& Cressey, G. 2009, GCA, 73, 4576.

Howard, K. T., Benedix, G. K., Bland, P. A., \& Cressey, G. 2011, GCA, 75, 2735.

King, A. J., Russell, S. S., Schofield, P. F., et al. 2018, MPS, 49, 62.

Kitazato, K, Milliken, R. E., Iwata, T., et al. 2019, Science, 364, 272.

Lauretta D.S., DellaGiustina, D. N., Bennett, C. A., et al. 2019, Nature, $568,55$.

Lee, M. R., Sofe, M. R., Lindgren, P., Starkey, N. A., \& Franchi, I. A. 2013, GCA, 121, 452.

Lee, M. R., Lindgren, P., \& Sofe, M. R. 2014, GCA, 144, 126.

Lindgren, P., Lee, M. R., Starkey, N. A., Franchi, I. A. 2017, GCA, 204, 240.

Marrocchi, Y., Gounelle, M., Blanchard, I., et al., 2014, MPS, 49, 1232.

Marrocchi, Y., Bekaert, D. V., \& Piani, L. 2018, EPSL, 482, 23.

O'Neil, J.R., Clayton, R.N. \& Mayeda, T.K. 1969, J. Chem. Phys. 51, 5547.

Petitat, M., Marrocchi, Y., McKeegan, K. D., et al. 2011, MPS, 46, 275.

Piani, L., Yurimoto, H., \& Remusat, L. 2018, Nat. Astron. 2, 317.

Pignatelli, I., Marrocchi, Y., Mugnaioli, E., et al. 2017, GCA, 209, 106.

Pignatelli, I., Marrocchi, Y., Vacher, et al. 2016, MPS, 51, 785.

Rubin, A. E., Trigo-Rodriguez, J. M., \& Huber, H. 2007, GCA, 71, 2361.

Rudraswami, N. G., Naik, A. K., Tripathi, R. P., et al. 2018, Geoscience Frontiers, 1-10.

Sakamoto, N., Seto, Y., Itoh, S., et al. 2007, Science, 317, 231.

Sugita, S., Tatsumi, E., Okada, T., et al. 2019, Science, 364, eaaw0422.

Sugiura, N., Fujiya, W. 2014, MPS, 49, 772.

Ushikubo, T., Kimura, M., Kita, N. T., Valley, J. W. 2012, GCA, 90, 242.

Vacher, L. G., Marrocchi, Y., Verdier-Paoletti, M. J., Villeneuve, J., \& Gounelle, M., 2016, ApJ L, 827, L1-6.

Vacher, L. G., Marrocchi, Y., Villeneuve, J., Verdier-Paoletti, M. J., \& Gounelle, M., 2017, GCA, 213, 271. 
544 Vacher, L. G., Marrocchi, Y., Villeneuve, J., Verdier-Paoletti, M. J., \& Gounelle, M.,2018, 545 GCA, 239, 213.

546 Vacher, L. G., Truche, L., Faure, F., et al. 2019, MPS, 23, 237.

547 van Kooten, E. M. M. E., Cavalcante, L. L., Nagashima, K., et al. 2018, GCA, 79, 102.

548 Verdier-Paoletti, M. J., Marrocchi, Y., Avice, G., et al. 2017, EPSL, 458, 273.

549 Vilas, F. 1994, Icarus, 111, 456.

550 Vilas, F., \& Gaffey, M. J. 1989, Science, 246, 790.

551 Watanabe, S., Hirabayashi, M., Hirata, N., et al 2019, Science, 364, 26.

552 Watkins, J. M., Nielsen, L. C., Ryerson, F. J., \& DePaolo, D. J. 2013, EPSL, 375, 349.

553 Young, E. D., Zhang, K. K., \& Schubert, G. 2003, EPSL, 213, 249.

554 Zolensky, M. E., Mittlefehldt, D. W., Lipschutz, M. E., et al. 1997, GCA, 61, 5099.

555 Zheng Y.-F. 1993, GCA, 57, 1079. 